\title{
Micro-Electrospray: Zeptomole/Attomole per Microliter Sensitivity for Peptides
}

\author{
Per E. Andren, Mark R. Emmett, and Richard M. Caprioli \\ Department of Biochemistry and Molecular Biology and Analytical Chemistry Center, University of Texas \\ Medical School, 6431 Fannin Street, Houston. Texas, USA
}

The micro-electrospray ionization source has been optimized for the specific analysis of neuropeptides such as neurotensin and methionine enkephalin. The source has the option of integrating nanoliter flow-rate desalting and preconcentration techniques into the micro-electrospray spray needle, eliminating post-column dead volumes. For neurotensin, the most sensitive neuropeptide analyzed thus far in this work, the injection of $10 \mu \mathrm{L}$ of a solution containing 320 zeptomoles $/ \mu \mathrm{L}$ gave an $[\mathrm{M}+3 \mathrm{H}]^{+3}$ ion at $m / z 558.4$ with $\mathrm{S} / \mathrm{N}$ of $>8: 1$. The MS/MS analysis of this peptide for the fragment ion at $m / z 578.9$ gave a S/N $>20: 1$ for a solution containing 32 attomoles $/ \mu \mathrm{L}$. (J Am Soc Mass Spectrom 1994, 5, 867-869)

W e have recently described the development of micro-electrospray (micro-ES) mass spectrometry for the high sensitivity analysis of peptides and proteins [1,2]. This was achieved using a modified Vestec electrospray source mounted on a Finnigan MAT TSQ 700 mass spectrometer and optimizing it for nanoliter flow rates $(300-900 \mathrm{~nL} / \mathrm{min})$ where the eluant was directly sprayed from a fused silica capillary needle. Dry ultrapure nitrogen was used as a carrier gas. For peptides, a $50 \mu \mathrm{m}$ (i.d.) 'spray' needle was packed with $1 \mathrm{~cm}$ of a reverse phase LC packing to act as a desalting/preconcentration device. This integrated sample processing/electrospray source allowed small volumes of dilute solutions to be analyzed; for example, the direct injection of 10 $\mu \mathrm{L}$ of a solution containing 100 attomoles $/ \mu \mathrm{L}$ of methionine-enkephalin produced an $[\mathrm{M}+\mathrm{H}]^{+}$ion at $m / z$ 574.2 with a signal-to-noise of greater than $5: 1$ obtained over a scan range of $m / z 550-600$. Sequence specific ions, e.g. the $A_{4}$ cleavage ion at $m / z$ 397.5, were scanned in the MS/MS mode after the injection of 10 $\mu \mathrm{L}$ of methionine-enkephalin from a 50 attomole $/ \mu \mathrm{L}$ solution onto the packed needle column.

We report here work designed to further optimize this source and thereby increase sensitivity for the specific analysis of neuropeptides. This approach is aimed at measuring these neurosubstances in various substructures of rat brain at endogenous levels, estimated to be in the attomoles $/ \mu \mathrm{L}$ range in dialysate, using a combination of microdialysis and mass spectrometry. In order to achieve the highest sensitivity, it was necessary to place the tip of the spray needle as

\footnotetext{
Address reprint requests to Dr. Richard M. Caprioli, Department of Biochemistry and Molecular Biology, University of Texas Medical School, P.O. Box 20708, Houston, TX 77225.
}

close as possible to the nozzle orifice so as to obtain maximum transfer efficiency of the sample. Thus, the spray needle, a $22.5 \mathrm{~cm}$ length of $50 \mu \mathrm{m}$ i.d. fused silica capillary containing an approximately $10-20 \mu \mathrm{m}$ i.d. orifice and $1 \mathrm{~cm}$ of $\mathrm{C}-18$ packing at the spray tip, was placed to within approximately $3 \mathrm{~mm}$ of the flat plate nozzle containing a $400 \mu \mathrm{m}$ orifice. Another problem addressed is the tendency of peptides in very low concentrations to bind to the internal surfaces of capillaries and injection valves. In order to minimize this effect for the analysis of dilute solutions of neurotensin, the entire sample path including the fused silica capillary and injector was coated with another peptide. This was done by continuously infusing 100 femtomole $/ \mu \mathrm{L}$ of substance $P$, a peptide known to adhere relatively strongly to fused silica, for $30 \mathrm{~min}$ utes at a rate of $0.82 \mu \mathrm{L} / \mathrm{min}$. This produced a low intensity signal at $m / z 674.4$, the $[\mathrm{M}+2 \mathrm{H}]^{+2}$ ion for substance $P$, which does not interfere with the analysis of neurotensin. Also, blank aqueous injections between each neurotensin sample analyzed were performed in order to verify that there was no carryover from sample to sample.

Overall, this methodology provided an increased sensitivity for neurotensin sufficient to give a $s / n$ of $5: 1$ for the injection of $10 \mu \mathrm{L}$ of a 320 zeptomole/ $\mu \mathrm{L}$ solution of the peptide, or a total injection of 3.2 attomoles. Figure 1 shows the narrow mass range scan of the $[\mathrm{M}+3 \mathrm{H}]^{+3}$ ion region for this analysis, where the peptide was desorbed off the stationary phase packing in the micro-ES needle by a $50 \%$ methanol/water solvent containing $0.25 \%$ acetic acid. The elution flow rate was $0.82 \mu \mathrm{L} / \mathrm{min}$, producing a peak width of approximately $15 \mathrm{sec}$. The spectrum shown in Figure 1 was produced by averaging scans of $0.5 \mathrm{sec}$ each at the apex of this LC peak (total averaged 


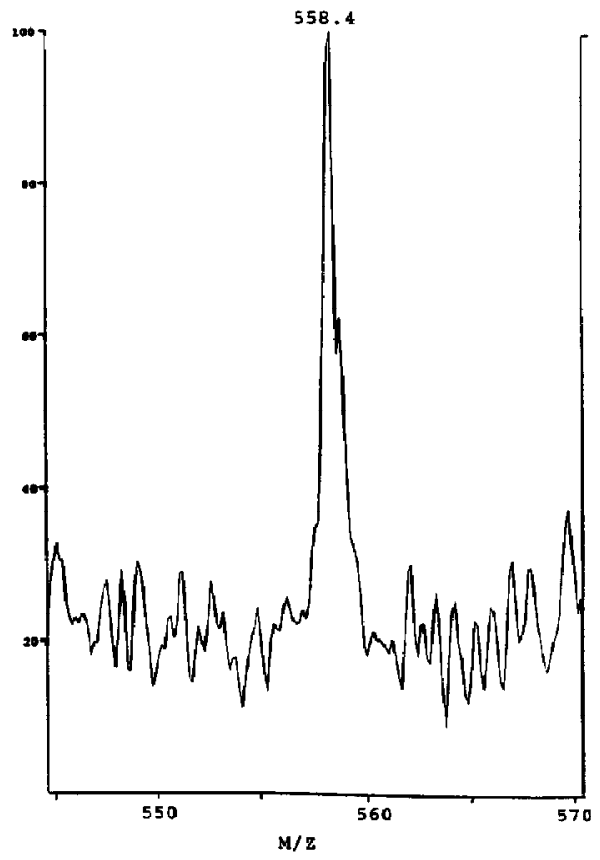

Figure 1. Direct injection of $10 \mu \mathrm{L}$ of a solution of 320 zeptomoles $/ \mu \mathrm{L}$ of neurotensin onto a $\mathrm{C}-18$ packed micro-electrospray needle with subsequent elution by $50 \%$ methanol $/ 0.25 \%$ acetic acid. The spectrum is an average of scans of $0.5 \mathrm{~s}$ each taken at the apex of an LC peak for about $5 \mathrm{~s}$ total width.

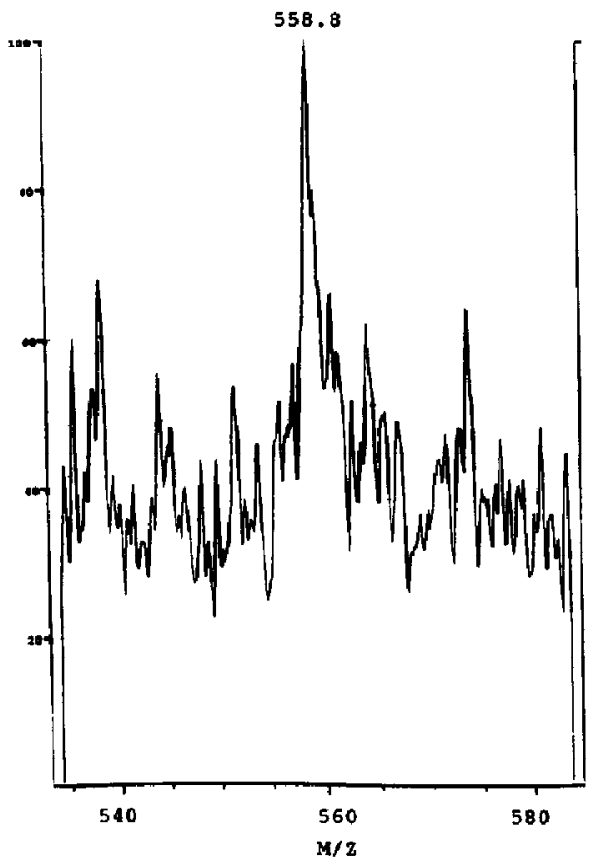

Figure 2. Continuous infusion of a solution of neurotensin containing 320 zeptomoles $/ \mu \mathrm{L}$ into the micro-electrospray source. This spectrum is an average of 16 scans of $0.5 \mathrm{~s}$ each, consuming a total of 35 zeptomoles of peptide.

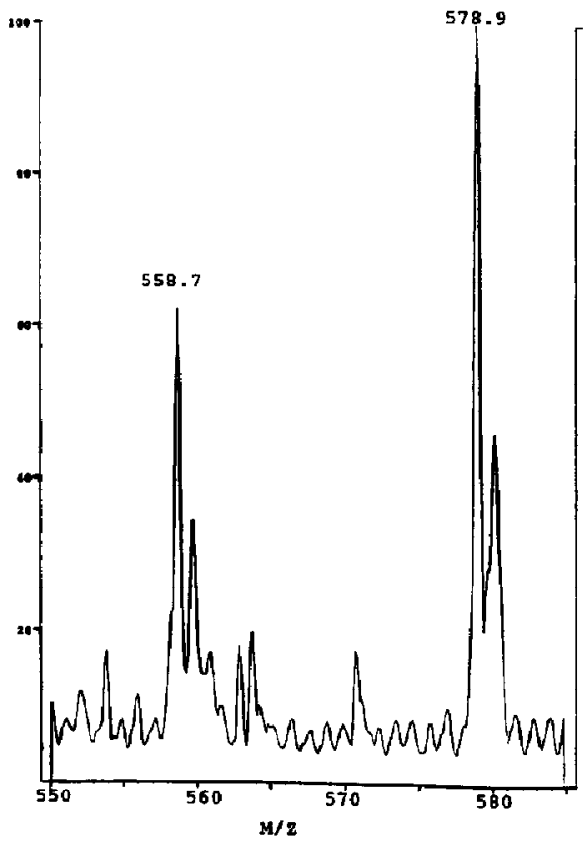

Figure 3. MS/MS spectrum of the $[M+3 H]^{+3}$ ion of neurotensin at $m / z 558.7$ and a doubly-charged product ion at $m / z$ 578.9 produced from the continuous infusion of a solution containing 32 attomoles $/ \mu \mathrm{L}$. The spectrum was obtained from an average of 16 scans of $0.5 \mathrm{~s}$, each consuming a total of 3.5 attomoles of peptide.

time about $5 \mathrm{sec}$ ). Another benchmark for sensitivity that is often used is the amount of sample 'consumed' in the time period required in producing a particular spectrum. Figure 2 shows the mass spectrum from the molecular $[\mathrm{M}+3 \mathrm{H}]^{+3}$ ion region of neurotensin obtained from the continuous infusion of 320 zeptomoles $/ \mu \mathrm{L}$ in $50 \%$ methanol containing $0.25 \%$ acetic acid flowing at a rate of $0.82 \mu \mathrm{L} / \mathrm{min}$. The spray needle in the ES source was similar to that described above except it did not contain C-18 packing. Approximately 35 zeptomoles of neurotensin was consumed during the acquisition of this spectrum obtained from an average of 16 scans of $0.5 \mathrm{sec}$ each.

MS/MS capabilities are also important in measuring endogenous peptides because of the highly structure specific nature of the analysis. Figure 3 shows the narrow $m / z$ range MS/MS scan for the $[\mathrm{M}+3 \mathrm{H}]^{+3}$ molecular ion region of neurotensin $(m / z$ 558.6) with collision decomposition to give the doubly-charged $Y_{5}$ fragment ion at $m / z$ 578.9, from the continuous infusion of 32 attomoles $/ \mu \mathrm{L}$ at $0.82 \mu \mathrm{L} / \mathrm{min}$. The spectrum shown in Figure 3 was obtained from the consumption of 3.5 attomoles of neurotensin using an average of 16 scans of $0.5 \mathrm{sec}$ each.

We conclude by noting that these results represent the highest sensitivity we have been able to achieve with this instrument. It was accomplished using a peptide which gives an abundant signal by electro- 
spray, using water solutions (not physiological salt solutions), and scanning relatively narrow mass ranges. For dialysate samples from live animals, for example, one could expect a lower overall detection limit for neurotensin of about 30 attomoles (total injected). The ultimate sensitivity achievable in a given experiment is dependent on the nature of the peptide of interest, and not all peptides will give the same results as neurotensin. For example, some other peptides we have tested, such as methionine-enkephalin and substance $P$, gave a 50-fold less intense signal than neurotensin for equivalent sample amounts. Nevertheless, these data provide a benchmark for the level of sensitivity that can be achieved under optimal conditions.

\section{Acknowledgment}

The authors thank NIH (grant 5 R01 GM 43783-05) for partial financial support of this work. P. E. Andren thanks the Swedish Medical Research Council and the Swedish Institute for partial support.

\section{References}

1. Emmett, M. R.; Caprioli, R. M. J. Amer. Soc. Mass Spectrom. 1994, 5, 605-613.

2. Caprioli, R. M.; Emmett, M. R.; Andren, P. E. Proceedings of the 42nd ASMS Conference on Mass Spectrometry and Allied Topics; Chicago, IL, May 29-June 3, 1994, Abstract 169. 